\title{
ECONOMIC EFFICIENCY OF A GAS-TURBINE TOPPING FOR STEAM REHEATING AT HEATING TURBO-INSTALLATIONS
}

\author{
Olga Romashova ${ }^{1 *}$, Leonid Belyaev ${ }^{1}$, Aleksandr Tubolev ${ }^{1}$, and Egor Skrebatun ${ }^{1}$ \\ ${ }^{1}$ Tomsk Polytechnic University, 634050, Tomsk, Russia
}

\begin{abstract}
The article considers the ways to improve the operating efficiency of conventional combined heat power plants using gas-turbine topping scheme allowing heat utilization of flue gases for steam reheating in the waste-heat steam boiler. The calculating analysis was performed for a steam-turbine power generating unit with a turbine of the T-110/120-130 brand name intended for various modes of operation.
\end{abstract}

\section{Introduction}

At the present stage of power engineering development the replacement of steam power cycle by combined one is one of the most efficient ways to improve performance of gas turbine thermal power stations. The coefficient of efficiency of combined cycle technologies is about $60-63 \%$ and allows saving $10 \%$ of fuel.

This work considers the ways to improve the operating efficiency of conventional combined heat power plants using gas-turbine topping scheme allowing utilizing heat of flue gases for steam reheating in the waste-heat steam boiler (WHB). The aim of this research is to estimate thermal effectiveness of steam reheating input in the basic cycle of a steam-turbine plant intended for various modes of operation of cogeneration turbine.

It is well-known that the use of conventional steam reheating in the combined heat power plant scheme leads to the increase of ventilating steam passage in the low-pressure section and thermal efficiency loss when operating in accordance with thermal schedule. Therefore, all cogeneration turbines with subcritical parameters of direct steam are designed without steam reheating. However, the rejection to use steam reheating leads to the decrease of thermal efficiency in the condensing mode on 3-4 \% due to the decrease of steam specific work in the turbine and does not allow the turbines of T-110-130, T-175-130 types competing with condensing units with similar initial parameters (K-210-130, K-160130) during the summer.

\section{Statement of problem and limitations}

The calculating analysis was performed for a steam-turbine power generating unit with a turbine of the T-110/120-130 type included in the steam-gas plant of heat recovery type.

\footnotetext{
* Corresponding author: roma@tpu.ru
} 
The schematic diagram of a steam-gas plant is illustrated in Figure 1. Steam wasted in a high-pressure cylinder of the T-110 turbine flows in the waste-heat steam boiler of a gas turbine. The remained portion of gas heat is utilized in low-pressure and high-pressure regeneration systems of a steam turbine (FWGH - feed water gas heater, CGH condensate gas heater). T,Q-diagram of the waste-heat steam boiler is shown in Figure 2.

Calculations were made for several modes of operation of the T-110-130 turbine: condensing mode by maximal possible volume steam flow rate in the condenser (mode I); in accordance with heating schedule with nominal heat supply from the turbine extraction (mode II); heat-extraction mode with single-stage preheating of heating-system water at minimal steam pressure in the controlled extraction and limited steam consumption at head of a steam-turbine (mode III).

Operation parameters of a gas-turbine part were defined from condensing mode and are invariable in heat-extraction modes. Temperature differences for some certain surfaces of the waste-heat steam boiler were estimated on [1]; waste-gas temperatures are accepted as $\theta_{\mathrm{w}}{ }^{\mathrm{WHB}}=100{ }^{\circ} \mathrm{C}$. In all modes the initial and final steam conditions are invariable $\mathrm{P}_{0}=12.8$ $\mathrm{MPa}, \mathrm{t}_{0}=555^{\circ} \mathrm{C}, \mathrm{P}_{\mathrm{k}}=0.0057 \mathrm{MPa}$. The condensing mode guaranteed by the manufacturing plant was taken as the design condition (initial parameters) for the T-110 turbine [2].

The following limitations were considered in the course of investigation $[2,3]$ :

- volumetric steam flow in the condenser $G_{k} \cdot v_{k}$ must not exceed the maximalpossible value, which defines geometrical dimensions of the final turbine stage. The input of steam reheating causes the increase of specific steam volume after steam reheating, which requires the reduction of mass steam flow consumption alongside the air-gas channel;

- pressure drop in chambers of controlled extraction leads to the electric power limitations (and main steam rate) due to the increase of bending stress in the blades of pre-extraction stages;

- vent steam flow for cooling of the low-pressure section by turbine operation in accordance to heating schedule depends on the temperature of steam coolant. The input of steam reheating leads to increase of steam temperature in the chambers of heat extraction and under other equal conditions requires the increase of vent steam discharge.

In addition, to ensure the turbine reliability by the input of steam reheating the strength calculation of the medium pressure section as well as the replacement of the material (steel) of air-gas channel components are required. The authors do not solve this problem in the framework of this work.

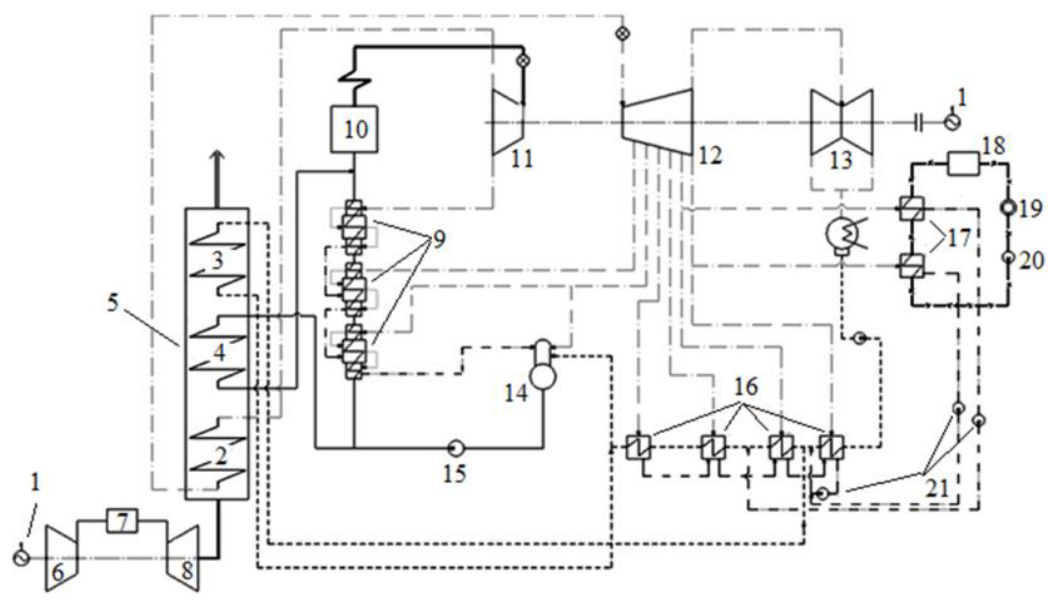


Fig. 1. Schematic thermal diagram of the steam-gas plant: 1 - electric generator; 2 - steam reheater; 3 - gas condensate heater; 4 - gas feed water heater; 5 - waste-heat steam boiler; 6 - compressor; 7 combustion chamber; 8 - gas turbine ; 9 - high pressure heater; 10 - boiler; 11 - high pressure cylinder; 12 - middle pressure cylinder; 13 - low pressure cylinder; 14 - deaerator; 15 - feed-pump; 16 - low- pressure heater; 17 - heating-system water heater; 18 - peak water-heating boiler; 19 - heat consumer; 20 - heating water pump; 21 - drainline pump.

\section{Efficiency calculation of steam reheating input in the thermal scheme of turbo-installation of T-110/120-130 type}

The calculation of thermal scheme on condensing mode was made by the variation of steam temperature in the hot leg of steam reheating. Constant volume steam flow in the condenser

$$
G_{k} \cdot v_{k}=\text { const }
$$

is considered as the basic limit in this mode. The maximal steam flow rate from the turbine in the basic scheme is assumed to be equal to $G_{k}=301 \mathrm{t} / \mathrm{h}$. The results of calculation of condensing mode are shown in Figure 2. The most efficient is the gas-turbine topping with the temperature of steam reheating which is equal to live steam temperature $555^{\circ} \mathrm{C}$.

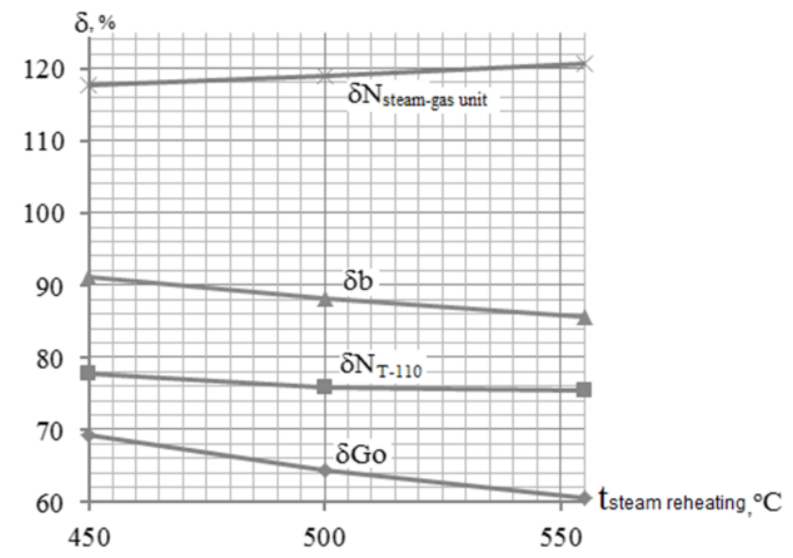

Fig. 2. The results of the calculation of the condensing mode of the T-110-130 turbine.

Therefore, steam consumption and its temperature in the inlet in WHB in the investigations of heat-extraction mode are taken from this scheme. Steam reheating till temperature of $555{ }^{\circ} \mathrm{C}$ leads to the reduction of specific reference fuel consumption on power generation on $14.3 \%$. The total capacity of the combined cycle gas turbine increases by $20 \%$ compared with the initial scheme, in spite of considerable electric power decrease (about $25 \%$ ) of a steam turbine.

The impact of steam reheating on the indices of plant operation in heat-extraction modes depends on the parameters of the heat supply system and consumer's load. For the mode II calculations were made by thermal load of extraction $\mathrm{Q}_{\mathrm{T}}=203$ megawatt and in the range from $0.098 \mathrm{MPa}$ to $0.25 \mathrm{MPa}$ of steam variation in the upper controlled extraction. Steam temperature after steam reheating is calculated in iteration cycle depending on steam consumption and steam temperature in the outlet of a high pressure cylinder and its rate is $450-470{ }^{\circ} \mathrm{C}$. Due to the decreased temperature of steam reheating compared with condensing mode and lower ratio of traditional regeneration of feed water in high and low 
pressure heaters, the volumetric steam consumption alongside the air-gas channel in these modes is lower than maximal possible values.

The studies show that the steam reheating by the operation of T-110-130 turbine on the thermal schedule decreases the electric power of a steam turbine on 11-13\% compared with its reference value due to the decrease of steam consumption in regenerative extraction by the increase of total capacity of the steam-gas plant on $39-44 \%$ and almost invariable thermal efficiency.

For the mode III in accordance to [3] the electric power of a steam turbine is limited by the value $\mathrm{N}_{\mathrm{E}}=80 \mathrm{MW}$, thermal load is equal to $\mathrm{Q}_{\mathrm{T}}=100 \mathrm{MW}$ by the pressure drop till minimal value of $0.03 \mathrm{MPa}$ in the lower heat extraction. Steam consumption on turbine is calculated for the initial basic scheme without steam reheating and is constant after the introduction of steam reheating $(100 \mathrm{~kg} / \mathrm{sec}$.). Since the main steam rate is considerably lower than maximal rate on turbine, steam temperature after steam reheating reaches its nominal value and gas reheating of feed water fully displaces the regeneration high pressure system (high pressure reheaters are disconnected) by the increase of feed water temperature. The highest electric power increment compared with the initial scheme was obtained in this mode. The capacity of a steam turbine increases from $80 \mathrm{MW}$ to $100 \mathrm{MW}$, specific reference fuel consumption on power generation decreases till $25 \%$ in spite of the increase of steam flow in the condenser.

Figure 3 and 4 illustrate the main results of calculations of considered modes.

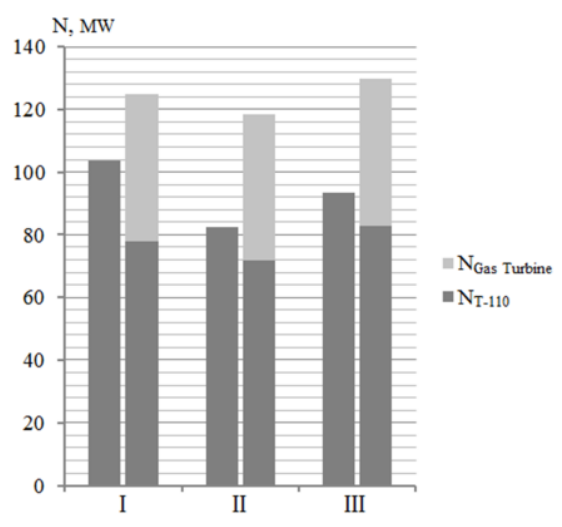

Fig. 3. The variation of the T-110-130 turbine power and steam-gas plant relative to the reference conditions of a steam turbine.

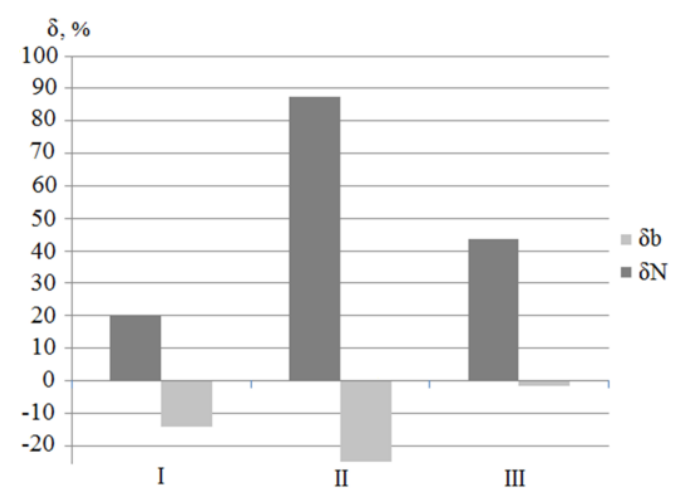

Fig. 4. The curves of electric power increment and fuel saving for a steam-gas plant relative to the reference conditions of T-110-130.

\section{Conclusion}

To sum up:

- $\quad$ in summer period when turbine of the T-110-130 type operates in the condensing mode the gas-turbine topping for steam reheating in the waste-heat steam boiler is able to reduce specific equivalent fuel consumption almost on $15 \%$ by simultaneous increase of electric power and steam turbine output on $25 \%$

- the use of steam reheating by T-110-130 operation in accordance with the heating schedule with nominal heat output to the external consumers does not cause any changes of thermal effectiveness of the plant, however, the electric capacity of this plant can be increased on 39-44\% compared with the initial design of the combinedcycle plant depending on the pressure in extraction; 
- maximal effect of the reheating input at cogeneration turbine becomes apparent for heat-extraction mode with minimal pressure in controlled extraction by limitation of steam flow at head of turbine. Electric power in a steam turbine recovers till rated power by the reduced flow consumption of the direct steam, while the total capacity of steam and gas part doubles compared to the initial scheme by the increase of thermal efficiency on $25 \%$.

- The introduction of steam reheating leads to the increase of reliability of a steam generating unit as well as live steam pipes and steam inlet elements of the turbine due to the consumption reduction of direct steam.

\section{References}

1. Tsanev S.V. Gas-turbine and steam-turbine installations of thermal power plants: Textbook for institutions of higher education (Publishing House MEI, Moscow, 2006)

2. Trukhniy A.D. Heat steam turbines and turbine plants: [textbook for institutions of higher education (Publishing House MEI, Moscow, 2006)

3. Instruction manual of heating unit of TG-8 brand name of Tomsk Regional Power Plant-2 